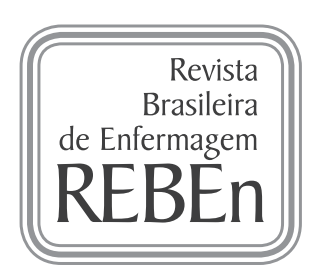

EDITORIAL

\title{
A Glance at the Good Practices of Nursing in Primary Care
}

\author{
Emiko Yoshikawa Egry' \\ ' Retired Full Professor of the Escola de Enfermagem of the Universidade de São Paulo. \\ Senior Professor, Department of Nursing in Collective Health, EEUSP. \\ Advisor for academic and research matters of the National Board of ABEn. Researcher Productivity CNPq \\ $1 A$ and Coordinator of CAEF of CNPq. Administration 2015-2018. São Paulo, Brazil.
}

\author{
How to cite this article: \\ Egry EY. A Glance at the Good Practices of Nursing in Primary Care. Rev Bras Enferm [Internet]. \\ 2018;71(3):930-1. DOI: http://dx.doi.org/10.1590/0034-7167.2018710301
}

From the point of view of Collective Health Nursing - field of theories and practices based on historical and dialectical materialism - (Good) Practices of Nursing, at any scope of action, must pursuit some assumptions and principles. I intend to focus on Health Care scope in this editorial, in other words, the range of articulated health tools provided to handle the monitoring, the intervention, the intervention evaluation in the health and disease processes of the territory's social groups.

Somehow, it should impact on both singular (where individuals are present, articulated with their families and relational groups in the daily living) and collective dimensions or social groups present in the territory to assist, in terms of health, in the context of social determination of the process.

I will highlight two relevant assumptions in this text for the Good Practices of Nursing in Primary Care (GPNuPC): a) Geopolitical territory of production and reproduction of life and work as a setting of GPNuPC; b) Scientific methodology as a basis of our actions: questioning genericity.

\section{a) Geopolitical territory of production and reproduction of life and work as a setting of GPNuPC}

Although several actions happen at home, and at the Basic Health Unit, geopolitical territory is the primary focus of GPNuPC. A territory or geopolitical space is where life is produced and therefore is where health needs and vulnerabilities appear. Vulnerabilities concern social groups, not risks. Risks focus on the understanding of individuals, normally targeting exclusively the biological and psychological body. However, the clinic is not about biological and psychological body only, as Foucault mentioned in "The Birth of the Clinic"(1). The clinical body is seen upside down in the territory, in other words, by identifying individuals in the sphere of social production and reproduction, their participation in social groups in the historically organized society, until reaching individuals and their families ${ }^{(2)}$. It is usually asked "in what geopolitical territory has this practice taken place?" In order to answer this question I need to know how social production and reproduction, political geography and environmental geography in this territory are. We need to know what epidemiological profile of different social groups living in that territory, municipality or a district of the municipality is. So, I actually need to go back. What drives the economy of the place? Who are these people? Where are they from? What are their ethnic and class origins? What are their jobs? What are their work relationships? Do not they have work relationships? Are they farmers? Do they possess large lands? Are they landowners? Are they owners of small companies, like the ones that manufacture hot-dog stands? Are they owners of hot-dogs stands or are they working for a company? Lastly, it is necessary to know how these people live and work, as part of life; and, moreover, how this has been historically taking place in the territory, the geopolitical history of the place; the history of social production of the place; and the social reproduction history of the place (consumption). That is why, instead of picturing the place, we need to know a little bit of how things work, like a movie, to say if this movie will end up well or bad, or if the contradictions brought about by subalternity of class, gender, ethnicity and generation are such that reality will change, but if there is no planned collective, and directed intervention to the individuals' autonomy, the objective reality may still be most difficult in people's lives. 
b) Scientific methodology as a basis of our actions: questioning genericity

Our caregiving needs theoretical support, the evidence produced by the research assures us that a care action will be positive ${ }^{(3)}$. I think that's a peaceful point, especially when it comes to the biological body. It will be? Evidence is the result of scientific investigations carried out with a group of people at a certain time and place. It can generate satisfactory results for the average person, however, they are not accompanied by a "package leaflet", that is, a list of possible side effects or iatrogenic effects. Let's take a very simple example, a nursing consultation with a pregnant woman performed by a nurse. As part of the consultation, the blood pressure was verified, placing the inflatable cuff in contact with the skin of the pregnant woman's arm. Let's say that the patient fully followed the protocol, in other words, waited 5 minutes after sitting, was not full bladder and had not smoked or run up the stairs. She was sitting comfortably in her chair without legs crossed. Did you follow the protocol? Yes, the blood pressure was normal and the rest of the consultation went perfectly well. After the consultation, the pregnant woman was expelled from her family, her first child was confiscated by the husband and her family of origin abandoned her to her fate. What happened? The pregnant woman was a Muslim who, according to the codes said by her later, a woman cannot be touched by another man. This is to understand that evidence shows scientific basis for care, usually thought of a generic human being, therefore for the average, but that may have serious iatrogenies like this that occurred with the Muslim pregnant woman. Social groups that are differentiated by ethnicity or race are also evidences that need to be applied in the care processes.

Finally, the intervention thought in a participatory way can take an emancipating perspective of the subjects. It seems too obvious to say that the intervention project in the health-disease process of individuals and their family should be thought with the user. The more people ignore caregiving processes, the less adherence they have to care plans. On the contrary, the more they understand care projects and their responsibility for achieving results, the better the development of social awareness, that is, that it is part of society ${ }^{(4)}$. For the GPNuPC, it is necessary to understand that the health-disease process is directly associated with the potential for erosion and strengthening of social groups, and that, along with values and counter-values arising from social reproduction processes, result in the biological, psychological and social status of the individual.

\section{REFERENCES}

1. Foucault M. Microfísica do poder. Rio de Janeiro: Graal; 1979.

2. Chaves MMN, Perna PO, Piosadlo LCM, Mafra MRP, Alessi SM. Territorialização em atenção primária à saúde/ estratégia de saúde da família. Porto Alegre: Artmed Panamericana. PROENF Atenção Primária e Saúde da Família. 2014. Ciclo 3 Volume 1 p. 9-42.

3. Lacerda RA, Nunes BK, Batista AO, Egry EY, Graziano KU, Angelo M, et al. Práticas baseadas em evidências publicadas no Brasil: identificação e análise de suas vertentes e abordagens metodológicas. Rev Esc Enferm USP [Internet]. 2011 [cited 2017 Jan 20];45(3):777-86. Available from: http://www.scielo.br/pdf/reeusp/v45n3/en_v45n3a33.pdf

4. Duncan P, Bertolozzi MR, Cowley S, Egry EY, Chiesa AM, França FOS. "Health for all" in England and Brazil? Int J Health Serv [Internet]. 2015[cited 2017 Jan 20];45(3):545-63. Available from: http://journals.sagepub.com/ doi/abs/10.1177/0020731415584558 